\title{
Hallazgos en resonancia magnética de las malformaciones uterovaginales: datos imprescindibles previos a una intervención quirúrgica
}

\author{
Cecilia Santos M. ${ }^{1}$, Manuela Martín I. ${ }^{1}$, Roberto Eduardo Correa S. ${ }^{1}$ \\ ${ }^{1}$ Servicio de Radiodiagnóstico. Hospital Universitario de Salamanca, España.
}

\section{RESUMEN}

La caracterización de las malformaciones congénitas del aparato genital femenino ha adquirido gran relevancia, principalmente en mujeres jóvenes con problemas de fertilidad. El origen de estas malformaciones procede de una alteración en el desarrollo embriológico de los conductos de Müller. El manejo terapéutico de estas entidades dependerá tanto del tipo de anomalía como de su gravedad. En la actualidad los múltiples avances tecnológicos en imagen permiten un diagnóstico preciso de estas malformaciones así como una posible planificación quirúrgica. Este trabajo tiene como objetivo revisar la clasificación de las malformaciones müllerianas así como estudiar los hallazgos en resonancia magnética que el cirujano debe conocer previo a la cirugía.

\section{PALABRAS CLAVE: Anomalías Müllerianas, infertilidad femenina, resonancia magnética}

\section{SUMMARY}

Morphologic characterization of congenital malformations of the female genital tract has acquired great importance, especially in the evaluation of female infertility. The origin of these malformations comes from an alteration in the embryological development of the Müllerian ducts. Technological advances in the field of radiology allow the diagnosis of these malformations, its possible treatment and surgical planning. This paper aims to review the classification of Müllerian anomalies and study the magnetic resonance findings that the surgeon should know prior to possible surgery.

\section{KEY WORDS: Müllerian duct anomalies, female infertility, magnetic resonance}

\section{INTRODUCCIÓN}

Las anomalías en el conducto de Müller son un grupo de entidades que resultan de un defecto en el desarrollo, en la fusión lateral o cervical o de un fallo en la reabsorción del tabique de los conductos de Müller en los diferentes pasos del desarrollo embrionario (1). En una revisión sistemática de estudios diagnósticos se encontró que la prevalencia promedio en la población general fue del 6,7\%, en la población infértil del $7,3 \%$ y en pacientes con pérdida gestacional recurrente del $16,7 \%$ (2).

La mayoría de los diagnósticos se establecen cuando la paciente comienza con problemas ginecológicos u obstétricos como infertilidad, abortos recurrentes, masas abdominales o amenorreas. Hasta en un $25 \%$ aproximadamente del total de casos se asocia a alteraciones renales o urológicas (3). 


\section{EMBRIOLOGÍA}

El desarrollo del tracto reproductor femenino se origina a partir de los conductos de Müller (conductos paramesonéfricos). Estos conductos son dos derivados mesodérmicos que crecen en sentido medial y caudal para originar las trompas de Falopio, el útero y los dos tercios superiores de la vagina (4). Los ovarios por tener un origen independiente no suelen verse afectados en las malformaciones uterovaginales (MUV). Las porciones inferiores se fusionan medialmente ("fusión lateral") y a continuación el septo central que separa los conductos fusionados se reabsorbe para dar lugar a una cavidad única. El tercio inferior de la vagina se forma a partir del seno bulbovaginal y se fusiona con los tercios superiores ("fusión vertical") (4).

Las anomalías de los conductos de Müller están causadas por una alteración en la embriogénesis. La formación completa y la diferenciación depende de la finalización de las 3 fases de desarrollo: organogénesis, fusión y reabsorción del septo (5).

La organogénesis se caracteriza por la formación de ambos conductos de Müller. El fallo en esta etapa supondrá una agenesia o hipoplasia uterina o un útero unicorne. La fusión se caracteriza por la unión de los conductos para formar el útero. Si existe algún fallo en esta etapa se formará un útero bicorne o didelfo. La reabsorción septal implica la resorción del septo entre los dos conductos fusionados, defectos en ese nivel ocasionarán un útero septado o arcuato. (5)

Es fundamental el conocimiento de la embriogénesis para entender este grupo de anomalías congénitas, ya que conociendo el momento en el cual se produce la alteración se determina el tipo de MUV (6).

Los conductos de Müller y de Wolff están íntimamente relacionados embriológicamente, por eso la asociación de anomías del sistema genital y del tracto urinario es relativamente frecuente. Es necesario examinar el sistema urinario en todas las pacientes con alteraciones uterovaginales (6).

\section{TÉCNICAS DE IMAGEN}

Las técnicas de imagen son esenciales para el diagnóstico, tratamiento y consejo reproductivo en pacientes con anomalías del conducto de Müller. Clásicamente las malformaciones han sido estudiadas mediante la histerosalpingografía y la ecografía. La histerosalpingografía está indicada en las primeras fases de evaluación de problemas de fertilidad. Proporciona información acerca del canal endometrial y cervical, así como de la permeabilidad tubárica. Sus principales inconvenientes son la falta de delimitación del contorno uterino externo y la exposición a radiación en pacientes jóvenes, que además suelen estar siendo estudiadas por problemas de fertilidad. (7)

La ecografía abdominal es un estudio que puede estar muy limitado debido al biotipo de la paciente, la posición uterina y la interposición de asas intestinales. La ecografía endovaginal nos permitirá una mayor resolución espacial. La histerosonografía con infusión de suero salino en la cavidad uterina mejora la delimitación del endometrio y la morfología uterina pese a que presenta las mismas limitaciones para delimitar los contornos externos que la ecografía. La ecografía 3D es una nueva técnica que está demostrando, en manos expertas, ser tan precisa como la resonancia magnética (RM), no obstante está limitada por la experiencia del operador (7). La RM es la técnica de elección debido a su alta precisión y delimitación de la anatomía uterovaginal (7).

\section{CLASIFICACIÓN DE LAS ANOMALÍAS DEL CONDUCTO DE MÜLLER}

El sistema de clasificación de la Sociedad Americana de Fertilidad es simple y fácil de utilizar. Se basa en la anatomía del aparato genital femenino, especialmente en la anatomía uterina en su estado actual (8). Según esta clasificación las anomalías se dividen en: Clase I: Agenesia e hipoplasia; Clase II: Útero unicorne; Clase III: Útero didelfo; Clase IV: Útero bicorne; Clase V: Útero septado; Clase VI: Útero arcuato; Clase VII: Secuelas de la exposición intraútero a dietilbestrol (DES).

\section{HALLAZGOS DE IMAGEN EN EL ESTUDIO DE RM}

La RM permite realizar estudios de imagen no invasivos con una precisión cercana al $100 \%$ en el diagnóstico de las MUV, evalúa las estructuras pélvicas en diferentes planos, delimita con fiabilidad la anatomía uterina interna y externa y permite realizar diagnósticos alternativos. Sus limitaciones se presentan por la presencia de artefactos de movimiento, por material metálico o por claustrofobia de la paciente (7).

Previa a la realización de la RM se aconseja la administración de antiperistálticos. El protocolo de la RM consiste en realizar secuencias Fast-Spin Echo potenciadas en T2 y adquiridas en los tres planos del espacio y en planos respecto al útero que proporcionan una información anatómica detallada, ayudan a identificar la posición y la orientación del útero y permiten definir el contorno externo del fondo uterino. Se realizan también secuencias en plano coronal que permitan valorar posibles anomalías del tracto urinario asociadas. Las secuencias potenciadas en T1 son útiles para descartar lesiones hemorrágicas (7). 
Clase I: Agenesia e hipoplasia (Figura 1). Suponen entre el 5 al $10 \%$ de las MUV. Se producen por un fallo temprano en el desarrollo embrionario, alrededor de la $5^{\text {a }}$ semana de gestación, resultando varios tipos de agenesia o hipoplasia del útero, del cérvix y de los dos tercios superiores de la vagina (5). El síndrome de Mayer-Rokitansky-KusterHauser es la malformación clase I más frecuente. Consiste en una combinación de agenesia vaginal completa con alteraciones uterinas. En un estudio reciente del 2013 se comprobó que hasta el 93\% de las pacientes mostraban úteros rudimentarios uni o bilaterales y solo un $8 \%$ presentaban agenesia uterina (9). Los síntomas se manifiestan en la pubertad como amenorrea primaria con características sexuales secundarias presentes, pues la función ovárica es normal aunque los ovarios pueden estar en localización ectópica $(5,9)$.
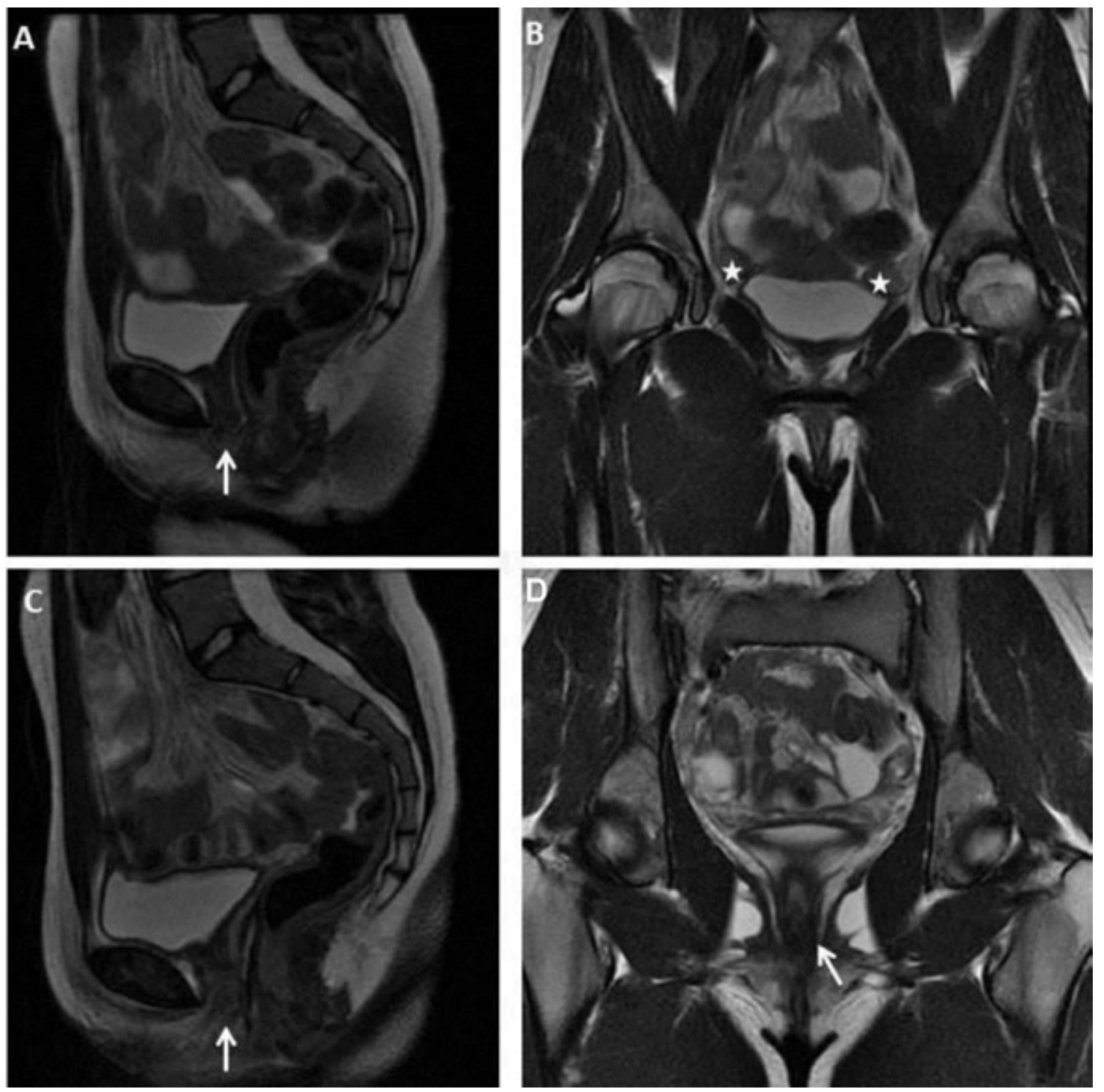

Figura 1. Paciente de 16 años con síndrome de Mayer-Rokitansky-Küster-Hauser. A y B: imágenes de RM potenciadas en T2 en sagital y coronal que muestran la ausencia de vagina entre la vejiga y el recto (flecha) con presencia de remanentes uterinos (estrellas). C y D: imágenes de RM potenciadas en T2 en sagital y coronal tras haberle realizado una intervención quirúrgica a la paciente, muestran la reconstrucción vaginal (flecha). 
El tratamiento puede ser quirúrgico y no quirúrgico. El no quirúrgico se basa en la dilatación progresiva con dilatadores o relaciones sexuales persistentes, para crear una neovagina por medio de la presión intermitente sobre el esbozo vaginal, utilizando dilatadores cada vez más grandes. El método quirúrgico consiste en el uso de injertos, ya sea con piel o tejido intestinal, o en la reconstrucción simple de la vagina. Una vagina septada obstructiva puede resecarse mediante vía vaginal, mientras que la no obstructiva puede no requerir tratamiento alguno, siempre y cuando no tenga efectos en la menstruación, en la actividad sexual, en la exploración física o en los procedimientos obstétricos (10).

Clase II: Útero unicorne (Figura 2). Un 20\% de las malformaciones se engloban en esta categoría. Esta anomalía se produce por un fallo en el desarrollo de uno de los conductos de Müller. Se pueden distinguir 4 tipos: cuerno rudimentario ausente, cuerno rudimentario no-cavitado (no funcional, sin endometrio funcionante), cuerno rudimentario cavitado y comunicado, cuerno rudimentario cavitado no comunicado. Este último se puede obstruir y requerir intervención quirúrgica. El útero unicorne es curvo y elongado y se encuentra lateralizado $(1,5)$. Es frecuente la asociación con alguna malformación renal (agenesia generalmente) (11). El tratamiento del cuerno obstruido con endometrio funcional consiste en la extirpación laparoscópica o por laparotomía (hemihisterectomía). Se sugiere practicar salpingectomía ipsilateral al cuerno resecado para evitar la remota posibilidad de embarazo ectópico (10).
Clase III: Útero didelfo (Figura 3). Es una anomalía poco frecuente, representa el 5\% de las malformaciones. Se produce por la falta de fusión lateral de los conductos de Müller. Cada conducto se desarrolla de forma independiente alcanzando un tamaño casi normal y con la presencia de dos cérvix $(1,5)$. En el $75 \%$ de los casos se asocia con un septo longitudinal vaginal y en menos ocasiones se asocia a un defecto en la fusión vertical que se traduce en un septo vaginal transversal unilateral $(1,5)$. El útero didelfo obstructivo requiere resección del hemisepto vaginal, en el resto de los casos no está indicada la cirugía. En caso de ser necesaria se efectúa metroplastia de Strassman (10).

Clase IV: Útero bicorne (Figura 4). Representa el $10 \%$ de las MUV. Se caracteriza por un fallo parcial en la fusión lateral entre los dos conductos de Müller, de manera que los dos cuerpos uterinos están fusionados sólo caudalmente. El miometrio central se puede extender hasta el nivel del orificio cervical interno (bicorne unicollis) o hasta el orificio cervical externo (bicorne bicollis) $(1,5)$. La superficie externa del fundus uterino es cóncava (a diferencia del útero septado). Las dos cavidades uterinas están comunicadas caudalmente (a diferencia del útero didelfo) y son más pequeñas que en éste (1). En la actualidad no está indicado el tratamiento quirúrgico salvo en las pacientes con aborto recurrente. El abordaje recomendado es la laparoscopia (10).

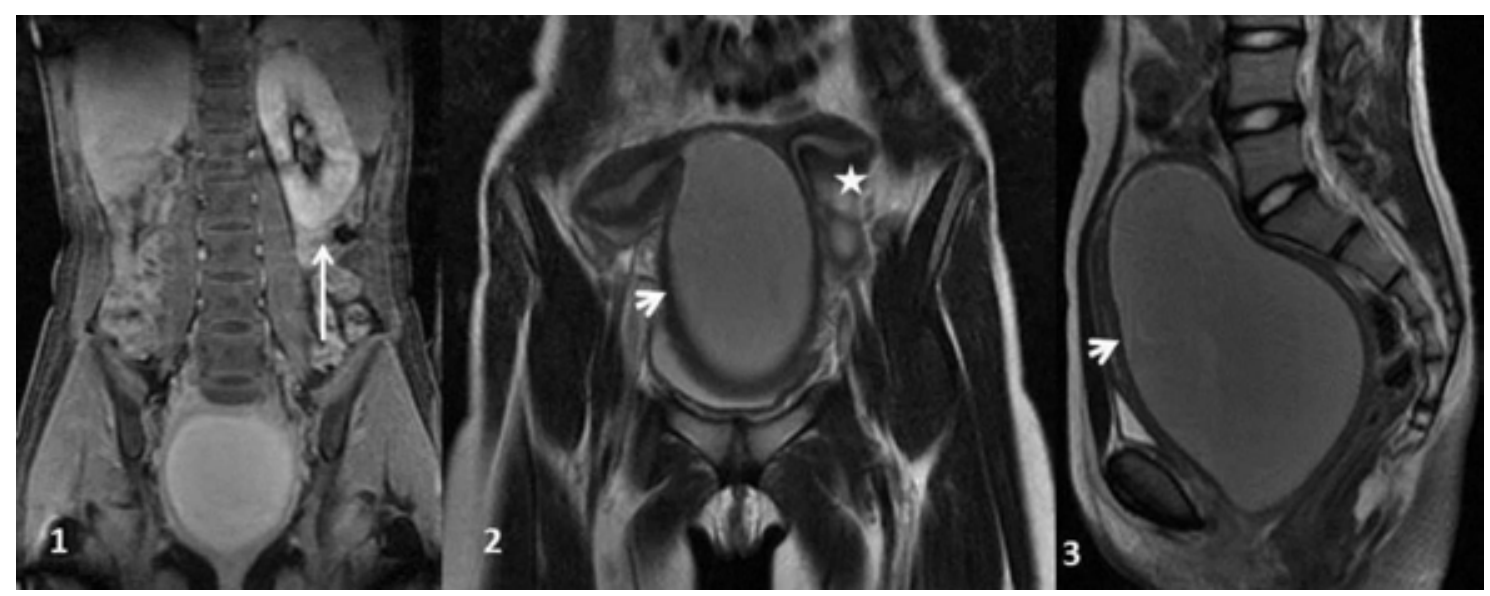

Figura 2. Mujer de 13 años que presenta un útero unicorne con cuerno rudimentario. 1: imagen coronal de RM potenciada en T1 que muestra un riñón izquierdo único (flecha). 2: imagen coronal de RM potenciada en T2 que demuestra severa dilatación de la cavidad endometrial derecha (cabeza de flecha) con un cuerno uterino izquierdo normal (estrella). 3: imagen sagital de RM potenciada en T2 donde se objetiva dilatación del cuerno rudimentario compatible con hematómetra (cabeza de flecha). 

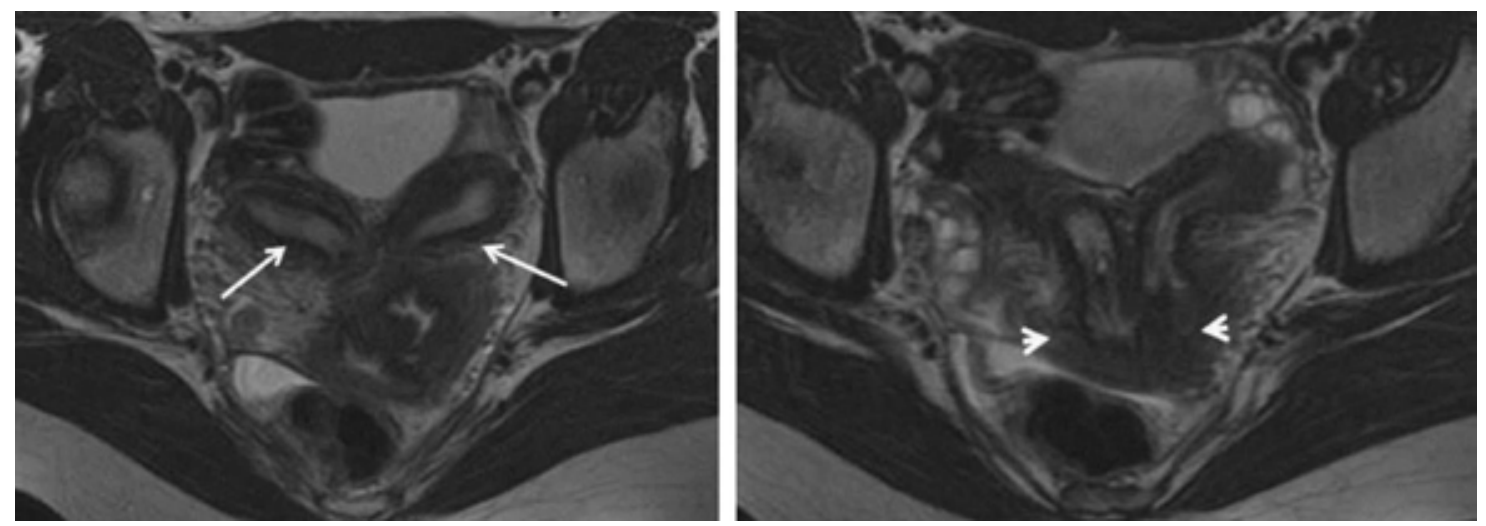

Figura 3. Imágenes axiales de RM en secuencias potenciadas en T2 que muestran un útero didelfo. Cada cuerno (flechas) presenta su propia cavidad endometrial y cérvix (cabezas de flecha).
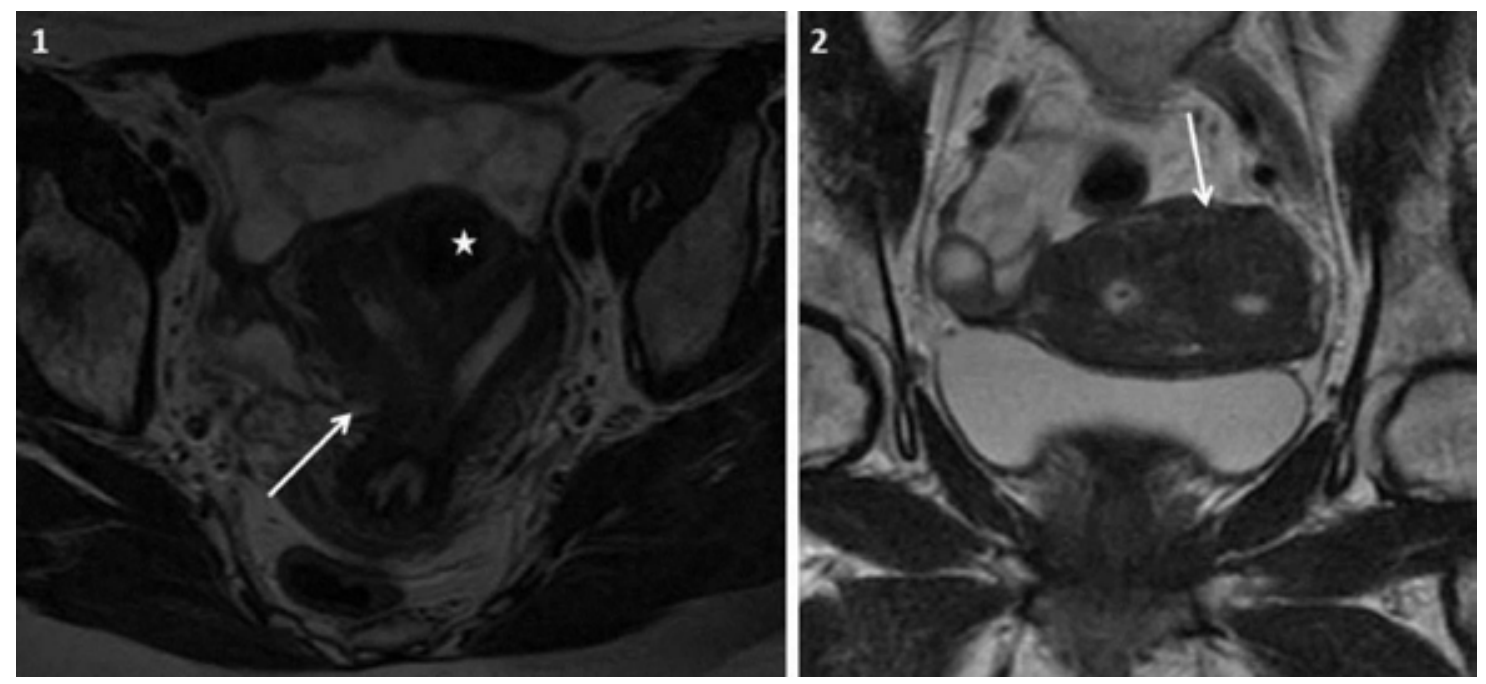

Figura 4. Imágenes axial (1) y coronal (2) de RM en secuencias potenciadas en T2 que muestran un ejemplo de útero bicorne (flecha) con comunicación con las cavidades endometriales en la porción inferior del cuerpo uterino. Se observa además un leiomioma (estrella) en la pared anterior.

Clase V: Útero septado (Figura 5). Es la malformación uterovaginal más frecuente (representa el $50 \%$ de todas las MUV) y con mayor incidencia de complicaciones reproductivas (7). Existe fusión lateral completa de los dos conductos de Müller pero con fallo en la reabsorción del septo central, con el resultado de dos cavidades uterinas separadas por un septo (como su nombre indica: "útero septado"). El septo puede ser muscular (con intensidad de señal similar al miometrio), fibroso o una combinación de ambos. Es importante distinguir un septo fibroso de uno muscular porque el primero puede ser reparado por vía histeroscópica y el segundo requiere cirugía transabdominal $(1,5)$. Característicamente el contorno externo del fondo uterino es normal, convexo, plano o ligeramente cóncavo $(<1$ $\mathrm{cm}$ ). El tamaño del útero es normal, aunque las dos cavidades que lo forman son individualmente más pequeñas (1). La metroplastia histeroscópica es el método de elección para el tratamiento de septos uterinos (10). 


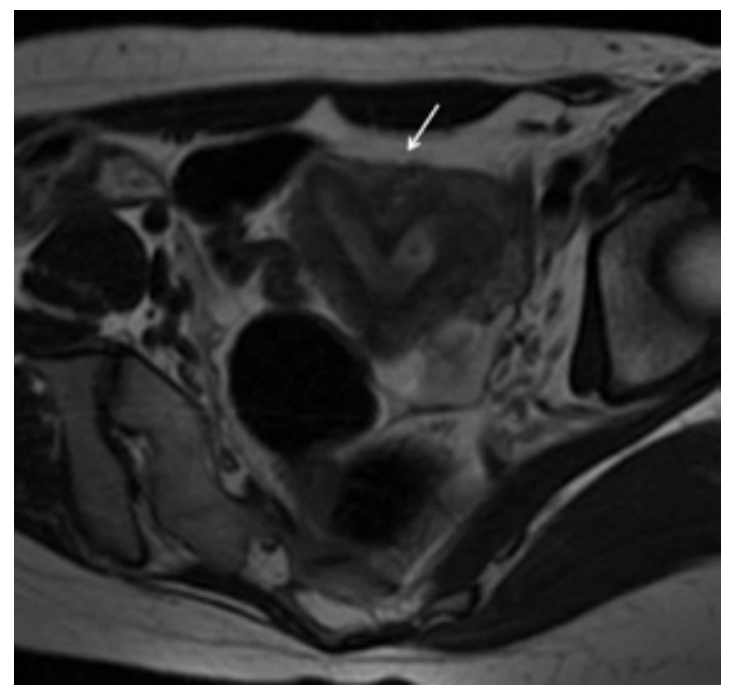

Figura 5. Imagen axial de RM en secuencia potenciada en T2 que muestra un útero septado con septo parcial. El fundus uterino es recto en este caso.

Clase VI: Útero arcuato (Figura 6). Se caracteriza por una sola cavidad uterina con contorno externo del fundus plano o convexo apreciando una identación suave del miometrio hacia la cavidad endometrial (que aproximadamentemide $15 \mathrm{~mm}$ ) $(1,7)$. Algunos autores los consideran una variante anatómica de la normalidad ya que no se asocia de forma significativa con un aumento en el número de abortos u otro tipo de complicaciones de otros subtipos de anomalías uterovaginales (5). Debido a que permite un embarazo normal en el $85 \%$ de los casos, la única razón para tratarlo es el aborto recurrente. El abordaje recomendado es la histeroscopia (10).

Clase VII: Secuelas de la exposición intraútero a DES. Millones de mujeres fueron tratadas con dietilbestrol para prevenir abortos espontáneos recurrentes, partos prematuros y otras complicaciones del embarazo. Posteriormente fue retirado del mercado por demostrarse una mayor incidencia de cáncer de vagina y de malformaciones uterinas en las hijas de las mujeres expuestas $(1,7)$. La imagen característica es la configuración en T de la cavidad endometrial. Otras anormalidades relacionadas son el útero hipoplásico, las bandas de constricción, un segmento uterino ancho, márgenes endometriales irregulares y defectos de repleción intraluminales. Todas pueden diagnosticarse por histerosalpingografía y ser corroboradas y tratadas por medio de

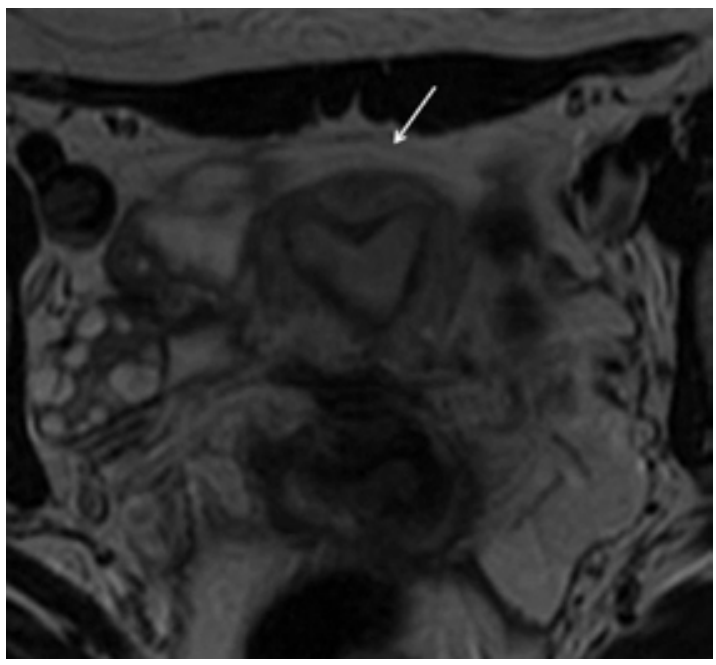

Figura 6. Imagen axial de RM en secuencia potenciada en T2 en la que se objetiva un útero arcuato con una cavidad única endometrial y un contorno uterino ligeramente convexo (flecha).

histeroscopia (10). Las anormalidades cervicales incluyen: hipoplasia, collar cervical y pseudopólipos, así como su asociación con la incompetencia cervical. El hallazgo vaginal más frecuente es la adenosis. No tienen corrección quirúrgica(10).

\section{DATOS ÚTILES ANTES DE LA CIRUGÍA}

Tamaño uterino: La forma y el tamaño del útero cambian según la edad reproductiva y la historia obstétrica de la paciente. En mujeres en edad reproductiva la longitud uterina mide entre 7 y $9 \mathrm{~cm}$. La relación entre el cuerpo uterino y el cérvix es 2:1 cuando es medido en el plano sagital (11).

Distancia intercornual: Se define como la distancia entre los extremos distales de los cuernos medida en las imágenes en eje largo y mide entre 2-4 cm $(1,11)$.

Anatomía zonal uterina: Es la diferenciación entre el endometrio (alta intensidad de señal), el miometrio interno (baja intensidad) y el miometrio externo (intensidad intermedia) en imágenes potenciadas en T2. Es normal verlo en mujeres en edad reproductiva (7).

Contorno del fundus externo: La morfología del contorno del fundus externo es importante para diferenciar entre útero septado y útero bicorne. Es muy importante hacer un buen diagnóstico porque la aproximación quirúrgica es diferente según la 
anomalía. Un útero septado es a menudo tratado con histeroscopia transvaginal con resección del septo. Un útero bicorne raramente necesita tratamiento quirúrgico, aunque a veces se realiza la metroplastia de Strassman con resección en cuña del aspecto medial de cada cuerno uterino y unificación de las dos cavidades. En pacientes con útero septado la metroplastia por histeroscopia puede mejorar sustancialmente la tasa de embarazos. Se estudia en imágenes de eje largo (11).

Septo uterino: Se debe informar de la presencia del septo uterino, su extensión y la intensidad de señal. El septo uterino puede estar compuesto por tejido muscular o fibroso. Es importante distinguir el tipo de tejido ya que el septo fibroso puede ser reparado por resección histeroscópica mientras que el septo muscular puede requerir una metroplastia transabdominal para asegurar la adecuada hemostasia debido a su gran vascularización (11). Un septo muscular tiene intensidad de señal intermedia en todas las secuencias de pulso, siendo isointenso con el miometrio. Un septo fibroso generalmente tiene una intensidad de señal baja en todas las secuencias. Además es habitualmente fino y lineal (11). Mediante el reconocimiento de la extensión inferior del septo uterino en el canal cervical y la cavidad uterina, las imágenes de RM pueden ayudar a diferenciar el útero didelfo del útero bicorne y el útero septado completo del incompleto $(1,11)$. Cuando evaluamos el útero después de una metroplastia histeroscópica no evidenciar septo o un septo residual que mida hasta $1 \mathrm{~cm}$ de longitud es considerado como una resección óptima (11).

Anomalías uterovaginales obstructivas: Precisan de atención inmediata. La RM determina con gran precisión el nivel de obstrucción permitiendo así un posterior drenaje y reparación. El útero distendido y lleno de sangre (hematómetra) y las trompas de Falopio con sangre (hematosalpinx) muestran las características típicas de señal de la sangre o de sus productos (11).

Vagina: Normalmente es vista como una cavidad de señal intermedia entre la vejiga y la uretra anterior y el canal anal posterior. La presencia, dirección y extensión de un septo vaginal deben ser informadas (1).

Gónadas: Ambos ovarios deben ser identificados. Cualquier lesión asociada como endometriosis o un tumor ovárico deben ser evaluados (11).

Anomalías asociadas: Una secuencia coronal potenciada en T2 debe ser realizada para el despistaje de anomalías renales o pélvicas debido a la alta prevalencia de ellas con las anomalías del conducto de Müller (10).

\section{CONCLUSIÓN}

Las malformaciones uterovaginales se presentan como anomalías congénitas en el desarrollo del conducto de Müller. Cuando se sospecha una malformación, la ecografía o la histerosalpingografía pueden ser realizadas como técnicas iniciales, sin embargo será necesaria la realización de una prueba más precisa que permita una mejor delimitación anatómica. La RM es fundamental para el estudio de las malformaciones previo a una posible cirugía. Es necesario conocer los datos radiológicos que pueden modificar la aproximación quirúrgica así como las posibles anomalías asociadas.

\section{REFERENCIAS}

1. Junqueira BL, Allen LM, Spitzer RF, Lucco KL, Babyn PS, Doria AS.Müllerian duct anomalies and mimics in children and adolescents: correlative intraoperative assessment with clinical imaging. Radiographics 2009;29:1085-103.

2. Saravelos $\mathrm{SH}$, Cocksedge KA, Li TC. Prevalence and diagnosis of congenital uterine anomalies in women with reproductive failure: a critical appraisal. Hum Reprod Update 2008;14:415-29.

3. Lankford JC, Mancuso P, Appel R. Congenital reproductive abnormalities. J Midwifery Womens Health 2013. doi: 10.1111/jmwh.12020.

4. Laufer MR, Goldstein DP, Hendren WH. Structural abnormalities of the female reproductive tract. En: Emans SJ, Laufer MR, Goldstein DP, eds. Pediatric and adolescent gynecology. 5th ed. Boston, Mass:Lippincott Williams \& Wilkins, 2005; 362-416.

5. Chandler TM1, Machan LS, Cooperberg PL, Harris AC, Chang SD. Mullerian duct anomalies: from diagnosis to intervention. Br J Radiol 2009;82:1034-42.

6. Madureira AJ, Mariz CM, Bernardes JC, Ramos IM. Case 94: Uterus didelphys with obstructing hemivaginal septum and ipsilateral renal agenesis. Radiology 2006;239:602-6.

7. Troiano RN, McCarthy SM. Mullerian duct anomalies: imaging and clinical issues. Radiology 2004;233:19-34.

8. American Fertility Society. The AFS classification of adnexal adhesions, distal tubal occlusion, tubal occlusion secondary to tubal ligation, tubal pregnancies, Müllerian anomalies and intrauterine adhesions. FertilSteril 1988;49:944-55.

9. Hall-Craggs MA1, Williams CE, Pattison SH, Kirkham AP, Creighton SM. Mayer-Rokitansky-Kuster-Hauser syndrome: diagnosis with MR imaging. Radiology 2013;269:787-92.

10. Jáuregui Meléndrez RA, Alanís Fuentes J. Estado actual de la clasificación, diagnóstico y tratamiento de las malformaciones müllerianas. Ginecol Obstet Mex 2013;81:34-46.

11. Saleem SN. MR imaging diagnosis of uterovaginal anomalies: current state of the art. Radiographics 2003;23:e13. 